\title{
Bilateral adrenal haemorrhagic infarction in a patient with antiphospholipid syndrome
}

\author{
Rebecca Louise Godfrey, ${ }^{1}$ James Clark, ${ }^{2}$ Benjamin Field ${ }^{2}$
}

${ }^{1}$ Frimley Health NHS Foundation Trust, Frimley, UK ${ }^{2}$ Surrey \& Sussex Healthcare NHS Trust, Redhill, UK

\section{Correspondence to} Dr Rebecca Louise Godfrey, r.godfrey1@uni.bsms.ac.uk

Accepted 30 October 2014

\section{SUMMARY}

A 68-year-old woman with antiphospholipid syndrome presented with a 3-day history of bilateral loin pain, vomiting, fever and confusion. On examination she was febrile, hypotensive and tachycardic. Investigations revealed raised inflammatory markers, renal impairment and hyponatraemia. Abdominal ultrasound revealed two well-defined heterogeneous areas bilaterally in the region of the adrenal glands. This prompted serum cortisol measurement and a CT of the abdomen. Cortisol was low in the context of sepsis at $48 \mathrm{nmol} / \mathrm{L}$, and CT confirmed bilateral heterogeneous adrenal pathology. The patient was managed for septic shock and adrenal insufficiency. She was recognised to have several risk factors for haemorrhagic infarction of the adrenals: antiphospholipid syndrome, sepsis, postoperative state and anticoagulant therapy. She was discharged well on glucocorticoid and mineralocorticoid therapy and a repeat CT at 4 weeks confirmed the diagnosis of bilateral adrenal infarct and haemorrhage.

\section{BACKGROUND}

This patient demonstrated classic clinical features of haemorrhagic infarction of the adrenals, and presented with several well-recognised risk factors. The case highlights the difficulty in recognising adrenal crisis in the context of sepsis, and the diagnostic value in CT alongside careful interpretation of serum cortisol.

\section{CASE PRESENTATION}

A 68-year-old woman with a history of antiphospholipid syndrome and hypertension presented to A\&E with a 3-day history of worsening bilateral loin pain, vomiting, fever and confusion. Her regular prescriptions were warfarin (target international normalised ratio (INR) range 3.5-4), atenolol and bendroflumethiazide. The bilateral loin pain developed initially over a $1 \mathrm{~h}$ period, and was described as a severe constant 'indigestion-like' pain, which progressed up her back over the first day. She noticed it less over the second and third day of pain, but became increasingly confused. The pain was $9 / 10$ in severity and unaffected by oral paracetamol. She vomited throughout this 3-day period, and was unable to retain any food or fluids. There was no haematemesis. She described feeling cold and sweaty, and recalled thinking that her appearance was unusually pale, with a grey tinge to her skin. She denied urinary symptoms and described constipation, with no bowel movements for roughly 1 week preceding admission. She denied weight loss, respiratory symptoms, chest pain or headache. She had not noticed any breaks in the skin, rashes or bruising.

Seven days prior to the onset of her symptoms, the patient had been discharged well following a right total hip replacement for osteoarthritis. On day 2 of her symptoms, a general practitioner (GP) visited the patient at home. Finding her to be febrile, the GP gave her a stat dose of nitrofurantoin.

On presentation to $\mathrm{A} \& \mathrm{E}$, she was pale and sweaty with a temperature of $38.2^{\circ} \mathrm{C}$ and cold peripheries. She was tachycardic (HR: $129 \mathrm{bpm}$ regular) and hypotensive (BP: $82 / 52 \mathrm{~mm} \mathrm{Hg}$ ). Glasgow Coma Scale was 14/15 (confusion). Her abdomen was soft and non-tender and there were no masses or organomegaly. No renal angle tenderness was documented. The site of the total hip replacement was unremarkable, with no sign of infection, and no other breaks in the skin, or rashes or bruising. Cardiac and respiratory examinations were unremarkable.

\section{INVESTIGATIONS}

An arterial blood gas on admission revealed metabolic alkalosis $(\mathrm{pH} 7.56)$ and hypoxia $\left(\mathrm{PO}_{2} 7.4\right)$, with a lactate of $1.3 \mathrm{mmol} / \mathrm{L}$. Blood tests revealed raised inflammatory markers $(\mathrm{C}$ reactive protein $194 \mathrm{mg} / \mathrm{L}$, white cell count $17.1 \times 10^{9} / \mathrm{L}$ ), impaired renal function (urea $8.6 \mathrm{mmol} / \mathrm{L}$, creatinine $167 \mu \mathrm{mol} / \mathrm{L}$; creatinine $83 \mu \mathrm{mol} / \mathrm{L} 1$ month previously) and globally deranged liver function tests (bilirubin $29 \mu \mathrm{mol} / \mathrm{L}$, alkaline phosphatase $220 \mathrm{iU} / \mathrm{L}$, alanine transaminase $71 \mathrm{iU} / \mathrm{L}$ ), with INR 4.6 (target $3.5-4)$. Amylase was within normal range (56 IU/L).

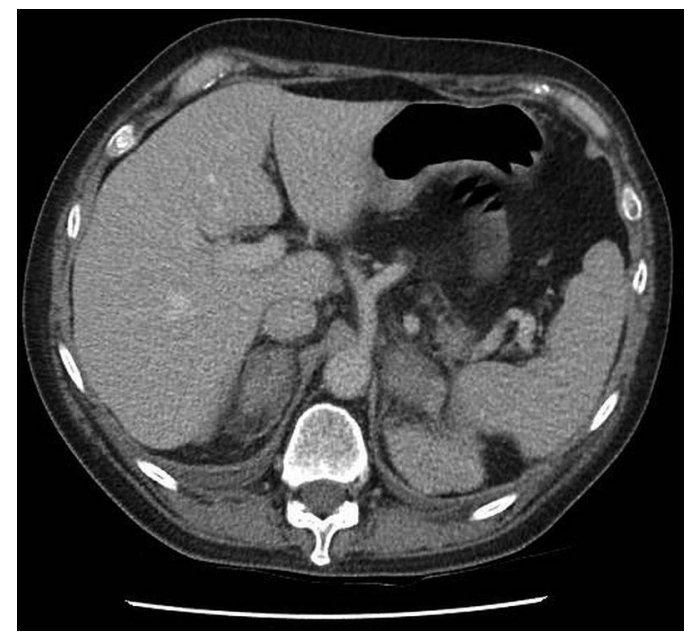

Figure 1 CT scan demonstrating bilateral adrenal masses and surrounding inflammatory/infiltrative opacities. 
Figure 2 Sepsis six (ABG, arterial blood gas; BP, blood pressure; $F B C$, full blood count; LFT, liver function test; MSU, mid-stream urine; U\&E, urea and electrolytes; IV, intravenous).

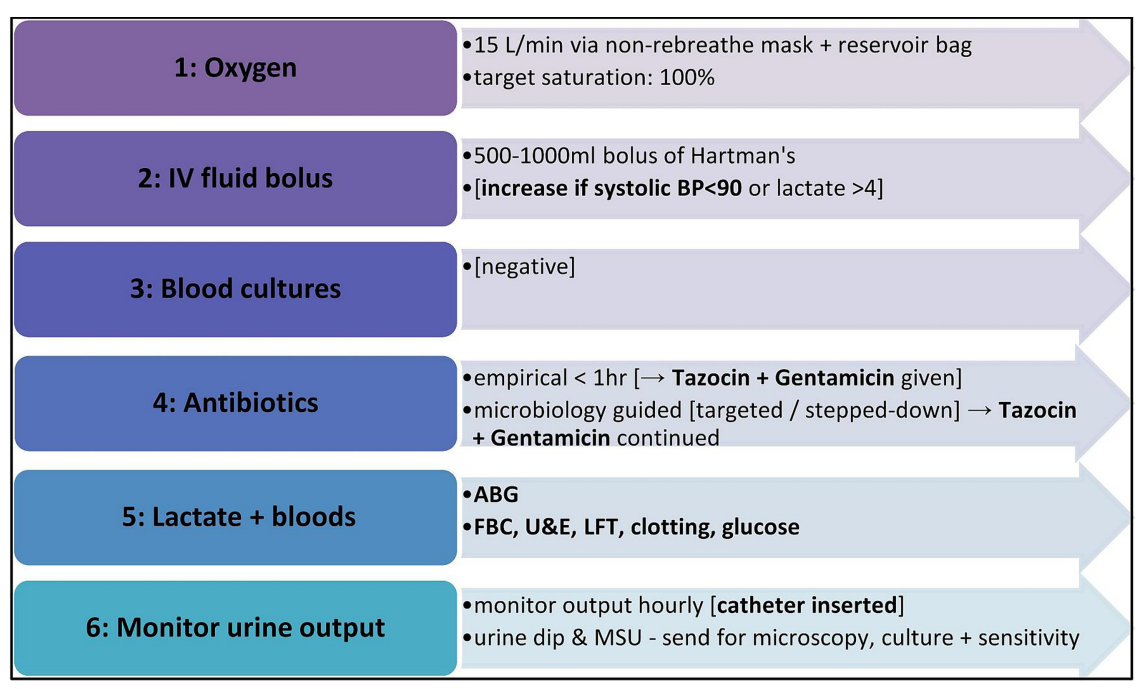

The patient was also hyponatraemic ( $\mathrm{Na} 132 \mathrm{mmol} / \mathrm{L})$ and hypokalaemic (K $2.4 \mathrm{mmol} / \mathrm{L}$ ). Urine dipstick revealed $2+$ blood, and was otherwise unremarkable. Blood glucose was $7.5 \mathrm{mmol} / \mathrm{L}$. Blood and urine cultures were negative.

ECG, chest X-ray and echocardiogram were unremarkable. Cortisol was extremely low in the context of sepsis at $48 \mathrm{nmol} / \mathrm{L}$, and abdominal ultrasound revealed two well-defined heterogeneous areas bilaterally in the adrenal gland region. CT scan confirmed bilateral heterogeneous adrenal pathology (figure 1).

\section{DIFFERENTIAL DIAGNOSIS}

Raised inflammatory markers and fever suggested an underlying sepsis, with an acute presentation of adrenal insufficiency indicated by low serum cortisol and sodium, and a strong suspicion of adrenal pathology on imaging. Low potassium could be explained by thiazide diuretic use and repeated vomiting. Concurrent sepsis and adrenal insufficiency resulted in profound hypotension.

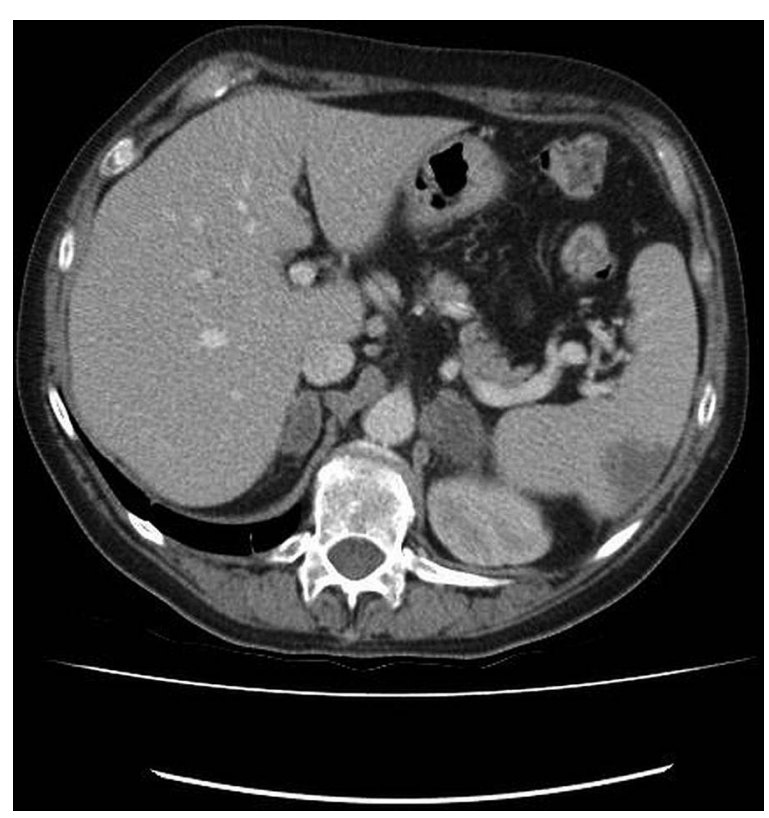

Figure 3 Follow-up CT scan at 4 weeks consistent with resolving bilateral adrenal infarct and haemorrhage.
Possible causes of this patient's adrenal insufficiency include:

- Bilateral acute adrenal infarct and haemorrhage:

- Risk factors included warfarin treatment but also the underlying hypercoagulable state (ie, antiphospholipid syndrome), sepsis and the postoperative state. ${ }^{12}$

- Stress precipitating acute crisis in the context of undiagnosed chronic adrenal insufficiency:

- This possibility seemed less likely as the patient had not previously reported malaise, anorexia, weight loss or hyperpigmentation and had recently undergone major surgery without mishap. ${ }^{3-7}$

\section{TREATMENT}

Initial management followed national guidelines for sepsis ('Sepsis Six') (figure 2). ${ }^{8}$

Adrenal insufficiency was diagnosed and high-dose intravenous hydrocortisone (100 mg every $6 \mathrm{~h}$ ) started alongside careful fluid resuscitation. This was tapered over 3 days to oral maintenance with hydrocortisone and fludrocortisone as the patient improved. She was discharged with a plan for repeat CT of the abdomen. No focal source of infection was identified.

\section{OUTCOME AND FOLLOW-UP}

Repeat CT of the abdomen 4 weeks later (figure 3).

Imaging is consistent with resolving bilateral adrenal infarct and haemorrhage. A splenic infarct is also apparent on CT.

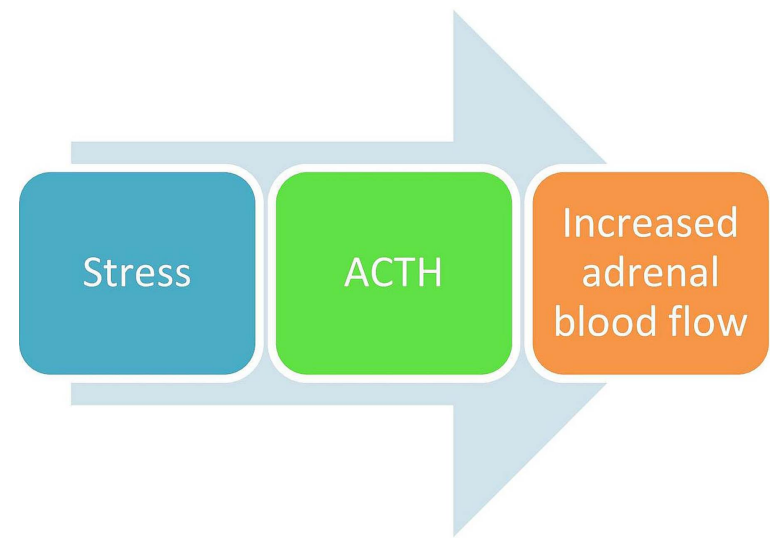

Figure 4 Hypothesised pathogenesis of haemorrhagic infarction of the adrenals in sepsis (ACTH, adrenocorticotropic hormone). 
Figure 5 Clinical presentation of haemorrhagic infarction of the adrenals.

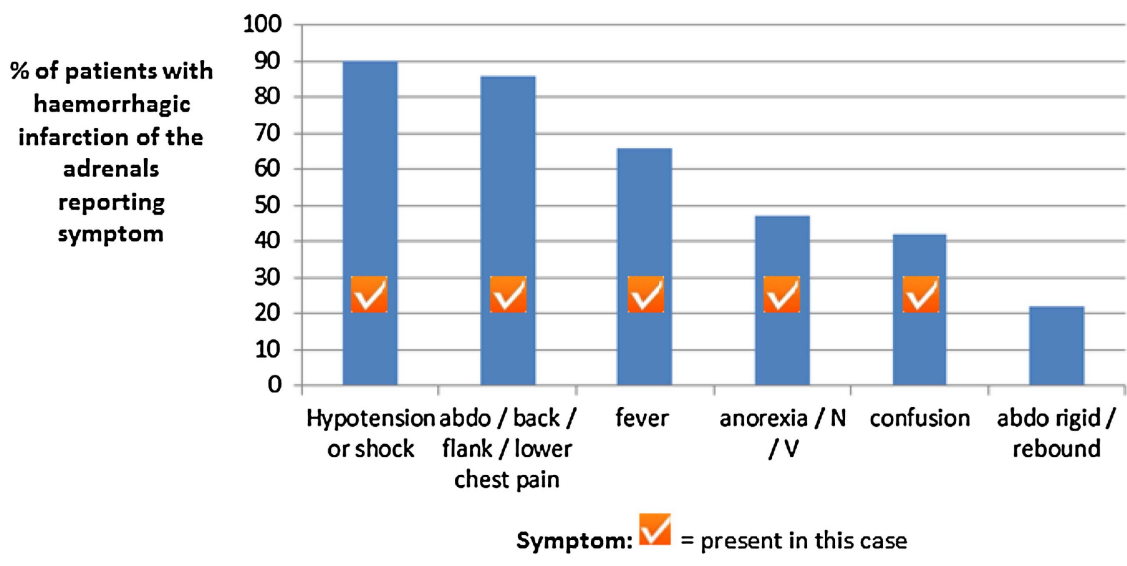

\begin{tabular}{|l|l|l|}
\hline$\checkmark$ & Anticoagulant therapy & $\begin{array}{l}\text { Although haemorrhagic adrenal infarction is usually } \\
\text { within the first 2-12 days of anticoagulant therapy }\end{array}$ \\
\hline$\checkmark$ & $\begin{array}{l}\text { Hypercoagulable states } \\
\text { such as antiphospholipid } \\
\text { syndrome }\end{array}$ & $\begin{array}{l}\text { Clotting test results usually within normal range } \\
\text { Spontaneous bleeding elsewhere is usually not } \\
\text { evident }\end{array}$ \\
\hline$\checkmark$ & The post-operative state & \\
\hline$\checkmark$ & Sepsis & Any cause of severe stress \\
\hline & Thromboembolic Dx & \\
\hline
\end{tabular}

Figure 6 Risk factors for haemorrhagic infarction of the adrenals. diagnostic tool and the potential for full recovery necessitate vigilance in the setting of hypotensive sepsis, with a low threshold for CT in patients with risk factors for haemorrhagic infarction of the adrenals.

\section{Learning points}

Acute adrenal insufficiency presents non-specifically and can mimic septic shock.

- The diagnosis should be considered in septic patients with risk factors such as antiphospholipid syndrome.

- Interestingly, patients with antiphospholipid syndrome may present with normal clotting tests and without signs of spontaneous bleeding.

- CT scan is the most useful diagnostic tool, and care should be taken in interpreting serum cortisol in acutely unwell patients.

Acknowledgements The authors thank the patient for taking the time to discuss the presentation and management of her illness, and for her consent to submit this report for publication.

Competing interests None.

Patient consent Obtained.

Provenance and peer review Not commissioned; externally peer reviewed.

\section{REFERENCES}

1 Nieman LK, Lacroix A, Martin KA. Literature review: clinical manifestations of adrenal insufficiency in adults. UpToDate 2013.

2 Rao RH, Vagnucci AH, Amico JA. Bilateral massive adrenal haemorrhage: early recognition and treatment. Ann Internal Med 1989;110:227-35.

3 Burke CW. Adrenocortical insufficiency. Clin Endocrinol Metab 1985;14: 947-6.

Patients with adrenal infarct and haemorrhage may recover adrenal function months later. ${ }^{14}$ The availability of an effective 
4 Dunlop D. Eighty-six cases of Addison's disease. BMJ 1963;2:887-91.

5 Irvine WJ, Barnes EW. Adrenocortical insufficiency. Clin Endocrinol Metab 1972;1:549.

6 Nerup J. Addison's disease-clinical studies. A report of 108 cases. Acta Endocrinol [Copenh] 1974;76:127-41.

7 Armstrong L, Bell PM. Addison's disease presenting as reduced insulin requirement in insulin dependent diabetes. BMJ 1996;312:1601-2.

8 Surviving Sepsis. Sepsis six pathway. Surviving Sepsis, 2012

9 Xarli VP, Steele AA, Davis PJ, et al. Adrenal haemorrhage in the adult. Medicine [Baltimore] 1978;57:211-21.
10 Migeon CJ, Kenny FM, Hung W, et al. Study of adrenal function in children with meningitis. Pediatrics 1967;40:163-83.

11 Margaretten W, Nakai H, Landing BH. Septicemic adrenal haemorrhage. Am J Dis Child 1963;105:346-51.

12 Nácul FE, Jardim A, MacCord F, et al. Hemodynamic instability secondary to adrenal insufficiency in a major burn patient. Burns 2002;28:270-2.

13 Annane D, Briegel J, Sprung CL. Comment on: corticosteroid insufficiency in acutely ill patients. N Engl J Med 2003;348:2157-9.

14 Feuerstein B, Streeten DH. Recovery of adrenal function after failure resulting from traumatic bilateral adrenal hemorrhages. Ann Intern Med 1991;115:785-6.

Copyright 2014 BMJ Publishing Group. All rights reserved. For permission to reuse any of this content visit http://group.bmj.com/group/rights-licensing/permissions.

BMJ Case Report Fellows may re-use this article for personal use and teaching without any further permission.

Become a Fellow of BMJ Case Reports today and you can:

- Submit as many cases as you like

- Enjoy fast sympathetic peer review and rapid publication of accepted articles

- Access all the published articles

- Re-use any of the published material for personal use and teaching without further permission

For information on Institutional Fellowships contact consortiasales@bmjgroup.com

Visit casereports.bmj.com for more articles like this and to become a Fellow 